\title{
Intensive Care Nurses' Experiences of Caring for Intubated Patients under Light Sedation: A Qualitative Study
}

\author{
Kajsa Bäcklund1, Karoline Persson1, Emina Hadziabdic ${ }^{2 *}$ \\ ${ }^{1}$ Blekingesjukhuset, Karlskrona, Sweden \\ ${ }^{2}$ Department of Health and Caring Sciences, Faculty of Health and Life Sciences, Linnaeus University, Växjö, Sweden \\ Email: *emina.hadziabdic@lnu.se
}

How to cite this paper: Bäcklund, K., Persson, K. and Hadziabdic, E. (2018) Intensive Care Nurses' Experiences of Caring for Intubated Patients under Light Sedation: A Qualitative Study. Open Journal of Nursing, 8, 473-484.

https://doi.org/10.4236/ojn.2018.87036

Received: May 4, 2018

Accepted: July 21, 2018

Published: July 24, 2018

Copyright $\odot 2018$ by authors and Scientific Research Publishing Inc. This work is licensed under the Creative Commons Attribution International License (CC BY 4.0).

http://creativecommons.org/licenses/by/4.0/

\begin{abstract}
Introduction: Previous studies have shown that a light sedation level is beneficial for intubated patients in the Intensive care unit (ICU). Aim: This study aimed to describe intensive care nurses' experiences of caring for intubated patients under light sedation. Methods: This study was an explorative descriptive qualitative study. Data were collected from 12 intensive care nurses by three focus group interviews and analyzed using qualitative content analysis. Findings: Five categories emerged from the data: 1) the importance of verbal communication and the nurses' presence, 2) feelings of frustration and heavy workload, 3) assessment of patients' pain and anxiety, 4) the nurses' desire for the development of guidelines, and 5) being inspired by the care. Conclusion: The study found that intensive care nurses were positive towards light sedation care but the organization of care did not support them as the patients cared for with light sedation treatments demanded their physical presence at patients' bed site.
\end{abstract}

\section{Keywords}

Intensive Care Nurse, Light Sedation, Experiences, Caring, Focus Groups, Qualitative Content Analysis

\section{Introduction}

Sedation of patients means relieving the patients' symptoms and lowering their level of consciousness. The purpose of sedation of critically ill patients is to relieve their pain and discomfort, to reduce anxiety, and to increase patient tolerance for nursing and support of the organ system [1] [2]. It has become increa- 
singly common for patients to be woken up from their sedation once a day or given light sedation while being ventilated. This places new demands on the care the intensive care nurse gives and on the environment, because the patient is awake but is not able to communicate verbally [3] [4]. However, previous studies have found that a light sedation level has a positive effect on the patient [5] [6] because it is easier for the patient to mobilize his or her own resources to get off the ventilator more quickly, which in turn leads to a decrease in physiological and psychological complications [1] [7]. A shorter respiratory time also reduces the risk of ventilator-associated pneumonia (VAP) [8]. Given the benefits of light sedation, the intensive care nurse has an important function in caring for these patients. An increased understanding of how the intensive care nurse experiences the care of the intubated patient under light sedation can increase the possibility to offer person-centered care as it makes clear the person's right to be involved in her/his own care [9]. Person-centered caring in intensive care unit (ICU) can be difficult to manage due to maintenance of patient identity, communication, the decision-making process, relationship development, nurse well-being and job satisfaction [10] [11].

Previous research into light levels of sedation has investigated the following: the effects of light sedation [5], factors that may affect sedation [12], the intensive care nurse's experience of the changes in the sedation management of patients [13] and caring for patients who are lightly sedated during mechanical ventilation [14]. The study [13] found that superficially sedated patients were more demanding and clearly increased nurses' daily workload. Another previous study [14] found that intensive care nurses experienced caring for superficially sedated patients as challenging. The challenge was that these patients demanded the nurses' attention more often, which required greater involvement by the nurses. On the other hand, the study found that nurses felt satisfaction when they could communicate with the patient. Nurses stated that being able to communicate with patients led to the provision of individualized care [14]. However, the aim of this study was to investigate the nurses' experiences of caring for intubated patients (i.e. those who have a tube down the throat) who are under light sedation.

Research concerning intensive care nurses' experience of caring for lightly sedated intubated patients is scarce and greatly needed for person-centered healthcare. This is to develop an appropriate individual sedation level [15] to allow the patient to take an active part in his or her own care and in the decision-making process in the ICU [10] [11], and to provide high quality healthcare and good accessibility of care for all patients [16] [17] [18].

\section{Aim}

The aim of this study was to describe intensive care nurses' experiences of caring for lightly sedated intubated patients. 


\section{Method}

\subsection{Design}

An exploratory-descriptive qualitative approach was used in order to obtain a better understanding of the studied field [19].

\subsection{Setting and Participants}

The study was conducted with participants from an ICU in a county council hospital during January and February 2016. The unit had 12 beds. Three of the beds were for isolated patients and one bed was reserved for children. In addition, this county council hospital intensive care unit offered advanced respiratory support (mechanical ventilation), cardiovascular and renal support and a respiratory care for prematurely born children. The unit had 17 anesthetists, 43 intensive care nurses and 25 assistant nurses. Nurses worked eight- and eleven-hour rotating shifts and there was a nurse: patient ratio of either 1:1 or 1:2, dependent upon the patients' condition.

The study was conducted using purposive sampling to ensure a range of informants of different ages, sex and working experience. The inclusion criteria for the study were that the informants should be registered nurses with specialist training in intensive care and experience in caring for lightly sedated intubated patients.

The deputy head of the intensive care department was contacted to obtain approval to conduct the study at the hospital and to invite people to participate. In consultation with the deputy head of department, three different times were set for the interviews, depending on the times that staff interested in participating could leave their workplace. The participants who were available at these interview times received oral and written information about the inclusion criteria and the purpose and ethical principles of the study, and were asked to participate.

The study population consisted of 12 registered nurses with specialized training in intensive care, including one man and 11 women, aged from 39 to 62 years (median 47 years), with experience of working in intensive care ranging from seven to 30 years (median 19 years).

\subsection{Data Collection}

Data were collected by three focus group interviews. A semi-structured interview guide was used in order to explore a variety of different experiences concerning the research topic from the standpoint of the informants themselves on a predefined set of issues [20]. The interview guide was based on the findings of previous studies [13] [14]. Examples of main questions are: "Please, tell us about your experiences of caring for intubated patients under light sedation? Please, describe a positive and a negative situation of caring for intubated patients under light sedation?"

A pilot test for the interview guide was carried out by three intensive care nurses who were not participating in the study. This pilot test led to minor cor- 
rections of language.

The focus group interviews were held in a secluded room outside the participants' workplace. Each focus group lasted about 30 minutes and included four persons. Three focus groups consisted of female participants, and one consisted of a man and three women. The moderator (KP, sometimes KB) guided the discussion and the assistant moderator $(\mathrm{KB}$, sometimes $\mathrm{KP})$ was present to operate an audio recorder and to take comprehensive notes. During the interviews, interaction between the participants was lively, with discussion and an exchange of experience and knowledge.

All the interviews were recorded and transcribed by the authors, KB and KP.

\subsection{Data Analysis}

Qualitative inductive content analysis was used to analyze data in order to identify patterns, variations and similarities [19].

During the analysis, the transcribed data were read repeatedly to obtain an overall picture. The authors reflected on the main content of the text and developed meaning units. Following this, they searched for similarities and patterns in order to develop categories from the perspective of the meaning units [19].

In order to achieve trustworthiness in this study, the following steps were taken: 1) in order to ensure credibility, analysis and then the formulation of codes, subcategories and categories was carried out by the first two authors (KB and $\mathrm{KP}$ ) and then they were reviewed and assessed for relevance by the third author (EH), who was experienced in qualitative studies and healthcare issues; 2) in order to ensure dependability, during the analysis process, accuracy, proximity and distance were followed by reading and re-reading of the material during all the analytical steps to check that each step was being followed; and 3)in order to ensure confirmability, it was ensured that the path from the meaning unit through condensation and coding to the subcategories and categories could be followed in the text [19].

\subsection{Ethical Considerations}

This study was conducted in accordance with the ethical principles of medical research involving human subjects established in Swedish law [21] and the Declaration of Helsinki [22]. According to Swedish law [21] approval by an official research committee was not required, as the present research posed no physical or mental risk to the participants and did not involve participants' personal data. The participants received written and verbal information describing the purpose and implementation of the study, stating that participation in the study was voluntary, and that they could terminate the interview at any time without notice. Furthermore, the participants were informed that the conversation would be recorded and that all data would be treated confidentially. For confidentiality, the collected data would only be used for the research purpose, the collected data and the transcripts would be anonymized and coded by numbers, and the analy- 
sis and presentation of the data would be done in a way that hidden the informants' individuality [21] [22].

\section{Findings}

Five categories: 1) the importance of verbal communication and the nurses' presence, 2) feelings of frustration and heavy workload, 3) assessment of patients' pain and anxiety, 4) the nurses' desire for the development of guidelines, and 5) being inspired by the care revealed the intensive care nurses' experience of the care of intubated patients under light levels of sedation.

\subsection{The Importance of Verbal Communication and Nurses' Presence}

The importance of verbal communication with the lightly sedated patient was a subject that was returned to frequently during the interviews. The nurses were aware that good verbal communication required that the information given should be understandable for the patient in order to involve them in their healthcare concerning nursing decisions and/or treatments. Therefore, the intensive care nurses felt that contact through verbal communication was important.

The intensive care nurses wished to involve the patients actively in their care. They felt a responsibility for ensuring that the patients understood the nursing interventions that they were performing. The willingness to help the patient through communication was strongly felt among all informants, and they were positive about spending extra time and resources to ensure mutual understanding between themselves and their patients. They were aware of the importance of good communication between nurse and patient, and their experience was that mutual understanding between them led to a good care relationship.

"It's important to get that contact with the patient so that the patient agrees with what we do. One who is very deeply sedated, maybe we say, now we will turn you around, and then we'll do that as well. But if you have a patient who can work against us or with us, it's better to get them to work with you, even though that takes more time" (Participant 3, group 2).

Communicating and trying to establish a relationship with the lightly sedated patient was experienced as more demanding, however. All the informants agreed that it was not always self-evident what the patient meant when he/she tried to communicate. Reading the patient's lips was not always easy and finding a way to understand each other required patience. However, there was a desire among the informants to have a good care relationship with the patient, despite the fact that this required more time and resources. Being able to communicate with the patient also helped the nurses to better understand the patients' healthcare situations.

The informants described caring for a lightly sedated intubated patient as a challenge. The challenge was how to fulfill the patient's need for the nurse's 
permanent presence. They stated that when their workload increased, and they were forced to attend to two patients at the same time, it was difficult when their both of patients needed help and at the same time, the lightly sedated patient constantly required their presence.

"...you can't let go of that patient to concentrate on another patient, you need to be present frequently..." (Participant 4, group 3).

\subsection{Feelings of Frustration and Heavy Workload}

All informants, during all three interviews, mentioned feelings and experiences of frustration. Although for the most part, the experience of caring for the lightly sedated patient was positive and inspiring among the informants, on the other hand they felt helplessness and frustration when they could not help the patient with pain relief and/or relieve suffering. Feelings of helplessness and frustration also appeared when different strategies in the patient's treatment were tried but nothing worked. The intensive care nurses felt responsible for the patient's feelings. They felt that it was important to provide good-quality care that included knowledge about the importance of finding a good balance between light sedation, pain relief and anxiety.

"It is a frustration within you when you' re not able to help them, when you can't do anything to make them better. You try, but you may still not get there during your shift' (Participant 3 , group 3 ).

The informants stated that it was impossible for every patient to have a light level of sedation. Nurses even described being emotionally affected when they saw that a patient had suffered because their duty was to understand the patient's view on his or her illness.

Despite a good knowledge of light sedation and what kind of care these patients needed, the intensive care nurses were sometimes forced to decline this kind of care when the workload was too great. Informants mentioned that in some situations their workload was heavy, which led to them being forced to refrain from the goal of keeping the patient under a light level of sedation. They felt frustration when they had the will and aim of trying to keep the patients in good condition under light sedation but staff levels and heavy workload affected the level of sedation.

"If we have many patients in bad condition, you will not be able to have them (patients with light sedation) under light sedation and awake as you wish; that's the truth, actually" (Participant 2, group 3).

\subsection{Assessment of Pain and Anxiety}

Every day, the intensive care nurses helped to relieve the patients' pain and anxiety, and the informants had a wide set of skills in this area. Yet, they had differing opinions about the assessment of pain and anxiety, with some of them feeling that it was easy to assess the level of the patients' pain and anxiety, whereas others found it difficult. 
"If a patient has pain, I notice that very well" (Participant 2, group 2).

"No, I think it's a bit difficult... I think the signs of the patient can be a bit difficult to read, if there is anxiety or pain..." (Participant 1, group 2).

The informants described different ways of trying to understand and assess anxiety and pain. Checking parameters such as blood pressure, respiratory rate and pulse was one method used, and anxiety and the patients' facial expressions affected the assessment.

It is understandable that it was not always easy to assess anxiety and pain. Interpreting parameters such as blood pressure and pulse along with facial expressions sometimes led to confusion in their assessments, although experience in healthcare and in having cared for many different patients who expressed pain and anxiety in different ways helped the intensive care nurses to identify the pain and/or the anxiety. However, the informants were well aware that they could not discern the pain and anxiety of all patients.

"We think we see it (pain andlor anxiety), but there may be those who look calm and still feel it (pain andlor anxiety). But otherwise you think you see the signs (of pain andl or anxiety) fast, you can see that this is not working... They're not feeling good" (Participant 2, group 3).

Intensive care nurses must always have the patients' current medical issues in mind in order to assess their pain and anxiety. If the patient had severe sepsis, with abnormal parameters of blood pressure, pulse and respiratory rate, it would be necessary for the nurse not to rely only on these parameters when making the assessment. The medical background of the patient could also be of value in the investigation if the patient experienced any pain or anxiety. Therefore, the patients' medical background was an important instrument for the intensive care nurses when they assessed pain and anxiety.

\subsection{Developing Better Guidelines for Medication Use}

The care of lightly sedated intubated patients required collaboration between all the professions in an intensive care unit. Sometimes when it was difficult to manage the patients' pain and anxiety, the informants felt that there was a lack of guidelines relating to how they should proceed in the care of the patient. There was also a need for guidelines when a lightly sedated intubated patient was not doing well; for example, when the patient was not responding to pain treatment, and when it was time to try a new kind of medication because the patient's anxiety had not been alleviated with the first medication. The nurses felt that it was difficult for them to decide how to proceed in the further treatment of the patient.

"... if we had some regime we could use, like we start with this and if that doesn't work we continue with this medication instead; you want it to be like that, but unfortunately it isn't..." (Participant 3, group 3).

\subsection{Being Inspired by the Care}

Informants felt inspired to care for lightly sedated patients, even though it de- 
manded more of the intensive care nurses in terms of time and resources. They felt satisfaction when they received a response from an intubated patient. Furthermore, they felt it was stimulating to be able to establish a relationship with the patient, to get a response from the patient and to see the person behind the sickness. The ability to establish contact with the patient created job satisfaction and was most valuable for them.

The intensive care nurses felt satisfaction and pleasure when an intubated patient tolerated a light level of sedation and could communicate their healthcare situation and "life world", because the positive effects of light sedation in intubated patients were well known by the informants.

"...sometimes it is so easy, the patient just lies there pointing while awake, completely calm; when it is like that it isn't any problem..." (Participant 1, group 3).

\section{Discussion}

In summary, the principle finding of the study was that intensive care nurses have a positive attitude towards light sedation care but the organization of care does not support them as the patients cared for with light sedation treatments demanded their physical presence at patients' bed site. Caring for these patients gave stimulus to their work, and positive responses from the patients contributed to their job satisfaction. On the other hand, it also required more involvement by the nurses because the patients had a greater need of their presence, both mentally and physically. Thus, the study found that the intensive care nurses had a positive attitude toward caring for these patients.

\subsection{Strengths and Limitations of the Study}

The strength of this research is that the focus group interviews allowed participants to express their views, which increased their comfort level and stimulated them to react to what was said by others, thereby leading to deeper expressions of their experiences, and also maximizing the quality of data [20]. A further strength of the study was that the focus groups were small, with four participants in each group. Small homogeneous focus groups with four participants are easier to recruit, and participants feel more comfortable with each other. Small groups are also preferable when the participants have great experience in the area, and discussion can occur. Homogeneity was characterized in the groups by the fact that the informants were intensive care nurses who were active in the same workplace. This gave the participants the opportunity to feel safe and to share their thoughts and experiences about the field in question [20].

One limitation could be that the recruitment of participants took place through contact with the deputy head of department, which could have affected the informants' willingness to participate in the study based on the hierarchic perspective above and beyond the workplace [23]. However, at the meetings where they were given information about the study, the participants were also 
informed that participation in the study was voluntary and that they could terminate the interview at any time without notice.

The findings from this study are contextual and can contribute to improved knowledge of the studied topic. They can also be transferred to other ICU with similar characteristics, as several intensive care nurses described similar practices [19].

\subsection{Discussion of the Findings}

Our study found that patients' ability to communicate verbally helped the intensive care nurses to understand and embrace the patients' healthcare situations and to build a caring relationship between the parties. It also gave a stimulus to the work being performed, and the responses from the patients contributed to the nurses' job satisfaction. A previous study [24] found that intensive care nurses emphasized the importance of seeing the patient as a unique individual with a personal life and history despite severe illness. Thus, good communication gave the patient the opportunity to make demands and make different choices, enabling the intensive care nurse to offer as high a level of care as possible [24].

This study's findings showed that more attendance, dedication and time were required to care for an intubated patient under light sedation. Being close to the patient and explaining what will happen to them are the most important tasks for the intensive care nurse [24]. However, the informants in this study described difficulties in finding the time for the commitment needed for the care of superficially sedated intubated patients, this finding mirror those of previous studies [14]. In this study, nurses' feelings of stress related to the heavy workload in the department, contributed to feelings of job dissatisfaction because the nurses were sometimes forced to decline this kind of care when the workload was too great. Intensive care nurse job satisfaction and workforce maintenance are aspects of patient-centered nursing [10]. Thus, the healthcare service should to continue to develop a positive workplace atmosphere supported with more workforce resources.

The results from this study showed that when caring for intubated patients under light sedation, it was difficult to assess the patient's pain and anxiety. Furthermore, objective parameters such as blood pressure and heart rate, and subjective signs such as the patients' body language and the nurses' personal experience were used to determine whether patients were bothered by pain or anxiety. The patients were mostly limited in their ability to communicate verbally, which meant that they communicated more with body language [25]. Another study found that a combination of personal experience and clinical signs was needed in the daily task of evaluating the patient's pain and anxiety [15]. In order to assess pain and anxiety, it is important that the nurse should be able to embrace the patient's emotional and physical state. The intensive care nurse's ability to understand how the patient experiences his/her body in the new situa- 
tion, and what the stay in an intensive care unit means, facilitates the assessment of the patient's experiences of pain and anxiety. The understanding of patients' emotional and physical difficulties creates an opportunity for the intensive care nurse to develop person-centered healthcare [9] [10] [26].

The present study found that the care of lightly sedated intubated patients was experienced as requiring more involvement in the form of the mental and physical presence of the intensive care nurses. Despite this, the nurses perceived that it was also inspiring to care for these patients, in agreement with previous studies [14] [24]. Our study found that it was important to be aware that caring for these patients required more involvement, time and resources from the intensive care nurse. The provision of more workforce resources and educational opportunities are necessary in order for nurses to be able to focus on the patient's active involvement in the care, tounderst and what is happening to the patient's body, and in turn to provide person-centered nursing.

\subsection{Conclusion and Implications}

The study revealed positive experiences of the care of intubated patients under light sedation. The patients' ability to communicate verbally facilitated the care being performed and the response from the patients contributed to the nurses' job satisfaction. However, the study found that there were also negative experiences related to the care of such patients, as it required more involvement from the intensive care nurses because the patients had a greater need for the presence of the nurses, both mentally and physically.

This study highlights the importance of raising awareness of how intensive care nurses experience the care of lightly sedated intubated patients, in order to provide an understanding of what this kind of care requires from the resources of the intensive care nurse. Increased understanding of the subject may be useful to the healthcare service in order to improve the policy frameworks that are needed to perform this care, which in turn would increase nurse job satisfaction and patient-centered nursing.

\section{Competing Interests}

The authors declare that they have no competing interests.

\section{Authors' Contributions}

$\mathrm{KB}, \mathrm{KP}$ and $\mathrm{EH}$ were responsible for the study conception and design and development of the interview guide. KB and KP carried out the data collection and performed qualitative analyses. $\mathrm{EH}$ helped in qualitative analyses. $\mathrm{KB}, \mathrm{KP}$ and EH drafted, revised and performed the drafting of the manuscript. All authors read and approved the final manuscript.

\section{Acknowledgements}

The authors are grateful to Anchor, English correction and proofreading service, 
for linguistic service of the manuscript.

\section{References}

[1] Selles, C.A. and Tjong, J.W. (2010) Conscious Sedation in the Intensive Care Unit: The Future? Erasmus Journal of Medicine, 1, 26-29.

[2] Garett, K.M. (2016) Best Practices for Managing Pain, Sedation and Delirium in the Mechanically Ventilated Patient. Critical Care Nursing Clinics of North America, 28, 437-450. https://doi.org/10.1016/j.cnc.2016.07.004

[3] Karlsson, V. (2012) Att vårdas vaken med respirator-patienters och närståendes upplevelser från en intensivvårdsavdelning [Being Conscious during mechanical ventilator Treatment-Patients' and Relatives' Experiences]. Institute of Health and Care Sciences, Sahlgrenska Academy, University of Gothenburg, Gothenburg.

[4] Holm, A. and Dreyer, P. (2018) Nurse-Patient Communication within the Context of Non-Sedated Mechanical Ventilation: A Hermeneutic-Phenomenological Study. Nursing in Critical Care, 23, 88-94.

[5] Egerod, I., et al. (2013) Sedation Practice in Nordic and Non-Nordic ICUs: A European Survey. Nursing in Critical Care, 18, 166-175.

https://doi.org/10.1111/nicc.12003

[6] Strom, T., Martinussen, T. and Toft, P. (2010) A Protocol of No Sedation for Critically Ill Patients Receiving Mechanical Ventilation: A Randomised Trial. The Lancet, 375, 475-480. https://doi.org/10.1016/S0140-6736(09)62072-9

[7] Nortvedt, P., Kvarstein, G. and Jonland, I. (2005) Sedation of Patients in Intensive Care Medicine and Nursing: Ethical Issues. Nursing Ethics, 12, 522-536. https://doi.org/10.1191/0969733005ne819oa

[8] Samuelson, K.A., et al. (2003) Intensive Care Sedation of Mechanically Ventilated Patients: A National Swedish Survey. Intensive and Critical Care Nursing, 19, 350-362. https://doi.org/10.1016/S0964-3397(03)00065-X

[9] Clarke, P.N. and Fawcett, J. (2016) Nursing Knowledge Driving Person-Centered Care. Nursing Science Quarterly, 29, 285-287. https://doi.org/10.1177/0894318416661110

[10] Jakimowicz, S., Perry, L. and Lewis, J. (2017) An Integrative Review of Supports, Facilitators and Barriers to Patient-Centred Nursing in the Intensive Care Unit. Journal of Clinical Nursing, 26, 4153-4171. https://doi.org/10.1111/jocn.13957

[11] Jakimowicz, S. and Perry, L. (2015) A Concept Analysis of Patient-Centred Nursing in the Intensive Care Unit. Journal of Advanced Nursing, 71, 1499-1517. https://doi.org/10.1111/jan.12644

[12] Guttormson, J.L., et al. (2010) Factors Influencing Nurse Sedation Practices with Mechanically Ventilated Patients: A U.S. National Survey. Intensive and Critical Care Nursing, 26, 44-50. https://doi.org/10.1016/j.iccn.2009.10.004

[13] Everingham, K., Fawcett, T. and Walsh, T. (2014) “Targeting” Sedation: The Lived Experience of the Intensive Care Nurse. Journal of Clinical Nursing, 23, 694-703. https://doi.org/10.1111/jocn.12058

[14] Tingsvik, C., et al. (2013) Meeting the Challenge: ICU-Nurses' Experiences of Lightly Sedated Patients. Australian Critical Care, 26, 124-129. https://doi.org/10.1016/j.aucc.2012.12.005

[15] Woien, H. and Bjork, I.T. (2013) Intensive Care Pain Treatment and Sedation: Nurses' Experiences of the Conflict between Clinical Judgement and Standardised Care: An Explorative Study. Intensive and Critical Care Nursing, 29, 128-136. 
https://doi.org/10.1016/j.iccn.2012.11.003

[16] SFS. Patientlag (2014:821). http://www.riksdagen.se/sv/dokument-lagar/dokument/svensk-forfattningssamling/ patientlag-2014821_sfs-2014-821

[17] World Health Organization and United Nations Office of the High Commissioner for Human Rights (2008) Human Rights, Health, and Poverty Reduction Strategies. Health \& Human Rights Publication Series, United Nations Office of the High Commissioner for Human Rights, World Health Organization, Geneva, 73 p.

[18] SFS (2017) Hälso-och sjukvårdslag. Health and Medical Services Act, 30.

[19] Patton, M.Q. (2015) Qualitative Research \& Evaluation Methods: Integrating Theory and Practice. 4th Edition, SAGE Publications, Thousand Oaks.

[20] Krueger, R.A. and Casey, M.A. (2015) Focus Groups: A Practical Guide for Applied Research. 5th Edition, SAGE, Thousand Oaks, 252 p.

[21] SFS (2003) Lag (2003:460) om etikprövning av forskning som avser människor. http://www.riksdagen.se/webbnav/index.aspx?nid=3911\&bet=2003:460

[22] WMA (World Medical Association) (2013) WMA Declaration of Helsiniki-Ethical Principles for Medical Research Involving Human Subjects.

https://www.wma.net/policies-post/wma-declaration-of-helsinki-ethical-principlesfor-medical-research-involving-human-subjects/

[23] Polit, D.F. and Beck, C.T. (2017) Nursing Research: Generating and Assessing Evidence for Nursing Practice. 10th Edition, Wolters Kluwer Health, Philadelphia, 784 p. https://doi.org/10.1016/j.iccn.2015.01.005

[24] Laerkner, E., Egerod, I. and Hansen, H.P. (2015) Nurses' Experiences of Caring for Critically Ill, Non-Sedated, Mechanically Ventilated Patients in the Intensive Care Unit: A Qualitative Study. Intensive and Critical Care Nursing, 31, 196-204.

[25] Vouzavali, F.J., et al. (2011) The Patient Is My Space: Hermeneutic Investigation of the Nurse-Patient Relationship in Critical Care. Nursing in Critical Care, 16, 140-151. https://doi.org/10.1111/j.1478-5153.2011.00447.x

[26] Leplege, A., et al. (2007) Person-Centredness: Conceptual and Historical Perspectives. Disability and Rehabilitation, 29, 1555-1565.

https://doi.org/10.1080/09638280701618661 